\title{
UNA FIGURA DE NICANOR PARRA
}

\author{
Demian Schopf \\ Pontificia Universidad Católica de Valparaíso \\ demianschopf@gmail.com
}

Conocí a Nicanor Parra cuando yo era un niño y no sabía lo que era el arte o la poesía. Menos sabía lo que era el vanguardismo y la antipoesía. Eran solo dos palabras más que, de repente, aparecían en la portada de un libro verde titulado Del Vanguardismo a la Antipoesía (1986). De vez en cuando me encontraba ese libro en diferentes lugares de mi casa. El primer recuerdo de Parra que tengo es en el living de ese mismo lugar-que hoy ya no existe- y recostándose sobre un diván morado con rayas negras. Decididamente exclamó: "yo voy a instalarme aquí" (o "aquí me instalo yo", no lo recuerdo bien). La segunda imagen es en su casa de La Reina, donde un toque de queda me sorprendió a mí y a mi familia. Tuvimos que quedarnos ahí hasta muy tarde. O hasta muy temprano. Ya siendo yo un adolescente, recuerdo a Parra en Las Cruces y con un chullo sobre su cabeza. Esa vez me causó gran impresión la profunda austeridad de ese lugar que parecía una instalación de Joseph Beuys. Finalmente, la primera vez que realmente hablé con él fue el año 2007, también en Las Cruces, y a propósito de una instalación mía llamada Máquina Cóndor ${ }^{1}$. Ese trabajo, programado, construido y expuesto el año 2006, había

$1 \quad$ Máquina Cóndor es una instalación que se presenta por primera vez en septiembre de 2006 en la Galería Gabriela Mistral, en Santiago de Chile. El trabajo incorpora, además, una pantalla publicitaria -en el centro de Santiago- y una página web. En la galería hay dos instalaciones donde pueden leerse 105 poemas generados cada 3,25 minutos. La primera consta de 90 tubos catódicos de 5 pulgadas dispuestos en una estructura construida con andamios; la segunda, de 12 televisores de 14 pulgadas dentro de idéntica armazón. Adicionalmente, dentro de la primera estructura, un poema es reproducido en tres paneles alfanuméricos, otro en un monitor de PC y un tercero es impreso por una impresora de formulario continuo (siendo el único que permanece en el tiempo; los demás, como la palabra hablada, desaparecen). Otra estrofa se despliega en el centro de Santiago y otra en www.maquinacondor.com. El motor de escritura opera con una estrofa del soneto De la Ambición Humana (1623) -de Luis de Góngora (1561-1627)- que es parcialmente poblada por palabras provenientes de la medicina forense y la cirugía. Un ranking en cinco diarios en la World Wide Web decide qué palabra se 
llegado a oídos del antipoeta. Lo que le interesó -y presumo que no sin escepticismo- fue la aparente vigencia de la vieja proposición, casi antitética, de que una máquina pueda escribir poemas o administrar 'poéticamente' un conjunto de palabras.

Suena a disparate que un artefacto mecánico pueda decir cosas poéticas del mundo o simplemente decir cosas que no estén ya todas contenidas en su propio mecanismo cuando éste se despliega completamente. En una ocasión, alguien calificó de "más bien magros" los resultados de otra máquina similar a las mías (a la fecha he construido dos). Se refería a lo generado por la Poetry Machine (2001) del artista, escritor, filósofo y programador alemán David Link. Y claro, lo relevante no es que la máquina escriba como Nicanor Parra o pinte como Leonardo da Vinci. Eso es tan imposible como ridículo sería pedirle a Tristan Tzara que fabrique antipoesía parriana con su Pour faire un poëme dadä̈ste de 1924. Aún así -y de manera muy sutil- es precisamente eso lo que la máquina de Tzara hace, o al menos una parte importante de lo que hace. Aunque elemental, lo de Tzara es una fórmula: un mecanismo. Y lo es en tensión con determinada idea de escritor, así como la antipoesía está en tensión con determinada idea de poeta y el Ready Made duchampiano con determinada idea de manufactura. El enunciado más básico parece ser que, si bien el poema no puede ser producto de un mecanismo - como creía Edgar Allan Poe-sí pueden concebirse fórmulas para desestabilizar -aunque sea provisionalmentecierta idea de poeta y por ende de poema, que aquí me atreveré a calificar como anidado en lo que Borges (Borges 8) considera una "tesis romántica". Lo de Tzara además de ser una fórmula es una máquina lógica que busca la (des[con])figuración del sentido. Se me perdonará que me exprese así. Y lo hace -el artefacto de Tzara- en algo tan banal como las oraciones impresas en un periódico. Busca, supongo, la figuración del caos como figura opuesta a determinada idea de poema, y por ende, a una igualmente determinada idea de lo que es el poeta y el proceso poético.

En Tzara lo poético no radica, desde luego, en la prosa producida, sino en el modo de producirla. Lo que está detrás de Tzara -o de Duchamp- no es el caos, el azar o el mero des-orden, sino una capacidad extremadamente aguda de comprender el momento histórico en que le tocó ser poeta. Lo mismo rige para la máquina de Link, donde los resultados constituyen, conjeturo, algo secundario.

Si bien el argumento que sigue es algo laxo -y si bien no voy a comentar precisamente una fórmula-algo de lo dicho hasta acá parece manifestarse en el siguiente poema de Parra:

instala en qué verso. Estos son: The New York Times, The Guardian, The Washington Post, The Miami Herald y The Economist. Ahí se buscan y "rankean" 300 términos vinculados con la guerra y la economía. Ese orden incide en la distribución de las palabras usadas en los versos, conjugando, de nuevo, guerra, economía, bíos y logos. A su vez, esos cuatro campos temáticos son cotejados con dos motivos del poema gongorino: el memento mori y la vanitas; locus recurrentes en el (neo)barroco de Máquina Cóndor: la Muerte atraviesa la Historia de la Cultura y de todas las culturas; de todo estilo artístico, de toda economía, de toda guerra y de toda biopolítica. 


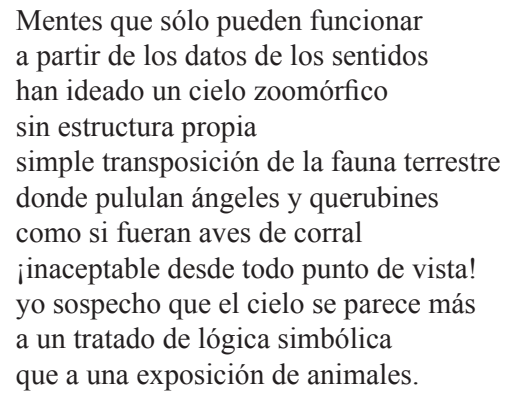

Se trata del XIV poema de los Sermones y Prédicas del Cristo del Elqui, publicado en 1977. Lo que más inmediatamente llama la atención -aunque no tanto en un antipoeta-es que en un poema se niegue a la metáfora como vehículo de lo poético.

En griego moderno se le llama metaphorikós a los medios de transporte. En un sentido parecido, algo -algo que Gottlob Frege llama sentido- es transportado, por ejemplo, cuando Miguel de Cervantes afirma que Dulcinea tiene cabellos de oro, o cuando espontáneamente una especie de uva, cuya forma es más alargada de lo normal, comienza a ser conocida como "dedo de dama". De hecho, nunca más pude comer dedos de dama - o brazos de reina- después de saber como se llamaban. Desde entonces, ambos me dieron asco. En casos como esos, el sentido reside en alguna semejanza. En el caso de la lógica simbólica no es exactamente así. Dicho gruesamente, ahí lo que otorga el sentido es lo que el primer Ludwig Wittgenstein llama "forma lógica de figuración". Que, por ejemplo, Margarita tenga cabellos dorados y Sulamith cabellos cenicientos no tiene mucho que ver con esa forma lógica de figuración a la que se refiere Wittgenstein.

Ambos ámbitos - metáfora y forma lógica- mantienen, no obstante, una relación de mínimo parentesco con los objetos a los que refieren. Como dice Wittgenstein (Wittgenstein 53): "como flechas: tienen sentido". Una de las muchísimas diferencias radica en que, en el ámbito de la lógica, la proposición con sentido posee un valor de verdad. La veracidad o falsedad de la proposición constituye algo relevante, en tanto que en el ámbito de la poesía es irrelevante si Margarita o Dulcinea tienen efectivamente cabellos que sean materialmente de oro. Las obras de arte no son verdaderas o falsas. Se me perdonará una disyunción tan elemental -y espero no estar obrando como esos "profesores españoles" a los que se refirió el mismo Tzara en otra ocasión- pero es la comparación entre cielo zoomorfo y lógica simbólica la que le da, precisamente, sentido.

Supongamos que al negar lo zoomorfo, Parra niega lo que se supone es constituyente de determinada idea de poesía y de determinada idea de literatura: la figura literaria.

Pero no niega solamente eso. Con respecto a lo zoomorfo del cielo, en psicología cognitiva existe un fenómeno que se llama "reconocimiento de patrones". Básicamente, esto se refiere a la imposibilidad de no ver, por ejemplo, formas que representan a otra cosa en las nubes o un rostro humano sobre la Luna cubierta de cráteres antropomorfos. Leonardo veía contornos de otros objetos en las manchas sobre una pared descascarada. Las manchas estaban ahí por otra cosa. Eran signos. Es imposible no ver figuras, y es 
utópico -atópico más bien- que la mente humana no figure, que no ordene y que no le dé sentido a lo que no lo tiene. De hecho, es esa misma mente la que organiza los datos de los cinco sentidos en un campo de conciencia unificado. Del sentido -y del sinsentido en el sentido (y viceversa) - no hay escapatoria, como lo demuestra, entre otras, la crítica del primer Wittgenstein a la lógica simbólica de Russell y Frege. Fue precisamente eso -el carácter pre-potente del sentido (que se manifiesta incluso en nuestra biología humana)- lo que hizo que en casi todas las culturas de la Tierra, por ejemplo, el cielo deviniera zoomorfo. Al parecer las mentes primitivas efectivamente solo podían funcionar a partir de los datos de los sentidos. Y fueron esas mismas mentes las que muchas generaciones después de inventar a las constelaciones, a Dios y al Cielo desarrollaron la lógica simbólica. Como se intuye -y como lo sostiene el segundo Wittgenstein- el lenguaje lógicamente perfecto es una consecuencia histórica del lenguaje natural. Igual que el lenguaje poético. Contra ese argumento hay poco que esgrimir. Y cada vez menos. En ese sentido, cabría imaginar que Parra -que estudió cosmología entre 1949 y 1951 en Oxford- alude a una vieja controversia: la existente entre el lenguaje natural y el viejo proyecto moderno de limpiarlo de impurezas lógicas -que los filósofos analíticos llaman despectivamente "literatura"-y así construir un lenguaje lógicamente perfecto. Para algunos filósofos analíticos ortodoxos -a estas alturas un tanto apolillados- la filosofía continental es, efectivamente, "literatura" y no "filosofía". Ese afán por un lenguaje lógicamente perfecto se extiende, por otra parte, más o menos desde el Órganon aristotélico hasta las actuales lógicas modales.

Pero esa vieja controversia sufre un vuelco fundacional a partir de los Fundamentos sobre la Aritmética de Frege y el fuerte influjo ejercido por éstos sobre el atomismo lógico de Bertrand Russell. Ese giro se conoce como linguistic turn y constituye el nacimiento de la filosofía analítica en oposición al idealismo alemán, que en esa época y lugar encarnaba el hegeliano Francis Bradley.

Es probable que ese fuerte rechazo insular a la "filosofía continental" -hoy ya en franca retirada- haya tenido algún impacto sobre Parra. Recordemos que éste estuvo en la isla entre 1949 y 1952. Podemos imaginar esa disyunción, expresada en el XIV poema de los Sermones y Prédicas del Cristo del Elqui, como balanceándose sobre un eje fundamental, que oscila -como el péndulo de un metrónomo- entre lo metafórico ("una exposición de animales") y lo no metafórico ("un tratado de lógica simbólica"). Uno de los puntos de ese mecimiento - uno de sus puntos más álgidos (si es que no el más)- es el que el primer Wittgenstein (Wittgenstein 69), siguiendo a Frege, formula así: "el lenguaje disfraza el pensamiento". Desde luego, con ese disfraz, Wittgenstein no se refiere a la lógica simbólica, sino al lenguaje natural. Ese que hablan todos los hombres y mujeres que no son mudos o sufren alguna enfermedad biológica o psicológica que los prive del habla. Los animales humanos hablan, así como las "aves de corral" aletean sin poder volar.

Las aves vuelan y los humanos hablan. El sentido es su "estructura propia". La poesía podría estar oculta, no obstante, precisamente en ese in-mundo disfraz: en el habla misma -que aglutina sentido y "estructura propia"-y, por lo mismo, en algo que no se puede agotar lógicamente, en el sentido de poder ser descompuesto analíticamente hasta 
llegar a lo que el primer Wittgenstein llama una proposición completamente analizada con un sentido completo.

Ese es el gran lugar común acerca del decir poético del que Parra intenta burlarse: que dice oblicuamente. Conjeturo, a estas alturas, que esa burla es solo aparente.

Antes de proseguir -y a propósito de disfraces y máquinas con cielos zoomorfos y lógica simbólica- quisiera agregar un dato curioso. Parra abandona Inglaterra en 1952. Ese mismo año, el informático británico Christopher Strachey programa, a modo de juego, un generador de cartas de amor en la computadora Ferranti Mark 1, a la que humaniza bajo el acrónimo M.U.C (Manchester University Computer).

M.U.C es quien firma las cartas de amor, que se generan rellenando casilleros con variables opcionales y manteniendo otras partes de la carta estáticas. Veamos un ejemplo:

DARLING SWEETHEART

YOU ARE MY AVID FELLOW FEELING. MY AFFECTION CURIOUSLY CLINGS TO YOUR PASSIONATE WISH. MY LIKING YEARNS FOR YOUR HEART. YOU ARE MY WISTFUL SYMPATHY: MY TENDER LIKING YOURS BEAUTIFULLY

M.U.C.

Acorde con la descripción que hace David Link (Link 15-42), el algoritmo de Strachey funciona de la siguiente manera: lo primero que hace es imprimir opcionalmente dos saludos, en este caso: Darling Sweetheart. Luego, el programa entra en un bucle que se ejecuta cinco veces, y que, dependiendo de una variable aleatoria, ensambla alternativamente dos patrones. Uno genera oraciones rellenando el siguiente esqueleto sintáctico: "You $\underline{\text { are } m y}$, adjetivo, sustantivo, sustantivo". El otro patrón es: " $\underline{M y}$, , sustantivo, adjetivo, verbo, adverbio, Your, adjetivo, sustantivo".

Aquí, y en el párrafo que acabamos de leer, las palabras estáticas -las que no varían nunca- aparecen subrayadas. La primera oración, que vemos en el ejemplo anterior, se ciñe al primer esquema; la segunda, al segundo. Finalmente, después de imprimir el bucle, el programa finaliza su escritura con un "Yours, adverbio, M.U.C."

Desde luego, aquí los resultados sí pueden calificarse de pobres, y el artefacto de básico. La pobreza de la máquina de Strachey -apenas un prototipo muy primitivo de otros experimentos por venir- radica en la esencial finitud de su base de datos; por más que puedan obtenerse 318 billones de cartas de amor diferentes todas ellas son predecibles (y esa limitación fundamental se extiende desde Ramon Llull hasta, digamos, el Landsberger Poesieautomat de Hans Magnus Enzensberger). Pero han evolucionado otras máquinas de lenguaje que han superado ese límite y que han roto esa barrera.

Volvamos al XIV poema de los Sermones y Prédicas del Cristo del Elqui. Es, por ahora, la estructura disyuntiva entre lenguaje natural (ese zoomorfo disfraz del cielo) y lógica simbólica (pensamiento lógicamente puro) la que me interesa. No se trata ya -como en Frege, Russell y Whitehead o Wittgenstein- de desnudar la forma lógica para acceder a ese pensamiento lógicamente puro, es decir, no disfrazado por el lenguaje natural -ordinario y cotidiano- al que Parra tanto le debe. El asunto es, al contrario, revestir ese esqueleto lógico invariante -esa "estructura propia" que brilla por su 
ausencia- con esos disfraces lingüísticos, a los que el primer Wittgenstein tanto temía (y a los que el segundo renunció definitivamente a combatir, resignándose al imposible intento de siquiera comprenderlos).

Naturalmente, la pregunta que surge es: ¿qué es aquello por lo cual el cielo está en el noveno verso de ese poema de Parra? Nótese que "cielo" está escrita con minúscula. No es el Cielo, aunque pululen por ahí "ángeles y serafines". Pienso que "estructura propia" sigue siendo un dato relevante, ya que, en rigor, no hay estructura propia, sino solo la existencia necesaria de algo que hace desfilar a los disfraces cuya forma es, no obstante, contingente, pero cuya existencia es, sin embargo, necesaria.

Con objeto de ahondar en este asunto, le pregunté al artista visual Gonzalo Díaz su opinión sobre el XIV Poema de los Sermones y Prédicas del Cristo de Elqui. Le leí el poema y le pregunté: “¿qué opinas de eso?”. Díaz respondió: “¡Inaceptable desde todo punto de vista! Falla de comienzo a fin. Resonancia extemporánea de las palabras "exposición de animales": ¿de cuando acá las mentes funcionan?; ¿acaso Parra no sabe que el cielo empieza desde los querubines para arriba?".

“¿Y que hay de ahí para arriba?”, volví a preguntar.

Gonzalo Díaz replicó: "para saber algo de eso hay que hacer la peregrinación a Colmar y mirar lo que debimos haber mirado hace 30, 40 años. ¡Qué lógica simbólica ni que ocho cuartos, this volumen presents Hume's Enquiry Concerning Human Understanding!: déjense de huevadas, Wir suchen überall das Unbedingte".

Al final de su segunda respuesta, Díaz cita el celebre aforismo de Novalis: "Buscamos por doquier lo incondicionado y encontramos siempre solo cosas". Resulta difícil no conjugar eso de que "encontramos solo cosas" con lo que para el filósofo analítico Ian Proops (Proops 106) constituye "una enigmática imagen metafísica" que "parece desprenderse de dos proposiciones del Tractatus" (Wittgenstein 39) Estas son:

2.0211 Si el mundo no tuviese ninguna sustancia, dependería que una proposición tuviera sentido, de que otra proposición fuese verdadera.

2.0212 En ese caso sería imposible trazar una figura del mundo (verdadera o falsa).

Buscamos en todas partes lo inmediato, lo incondicionado y lo que es sin mediación; el ser, a fin de cuentas (el gran problema de la metafísica occidental). Sin embargo, encontramos, siempre, que solo hay figuras, sean cielos zoomorfos o tratados de lógica simbólica. Todo el problema del Tractatus habrá consistido, entonces, en mostrar que el ser -lo incondicionado- no es, para la filosofía, otra cosa que un malentendido lingüístico, es decir, la confusión de un concepto general -es decir, de una mera generalización- con una cualidad real compartida por todas las cosas que existen. De Jena a Cambridge y de Cambridge a Viena, la metafísica occidental es, en consecuencia, un malentendido lingüístico y un conjunto de sinsentidos que, paradojalmente, solo pueden leerse con sentido. Esa es la única "estructura propia" del animal humano, condenado al sentido por tener el cuerpo que tiene. Y es él el que exige al pensamiento y a la lengua, que, quizás, son solo extensiones de los cinco sentidos que constituyen ese armatoste biológico al 
que Aristóteles caracterizaba como un navío piloteado por un alma. Pero no es este el lugar para instalar una controversia acerca de que tan dependientes, o independientes, son estados mentales -que se expresan en sensaciones, pensamientos, palabras y conceptos progresivamente más y más abstractos- respecto al cuerpo y al mundo en el que tienen lugar. Más acá de eso, el sentido es, a todas luces, un mono con navaja y también con una brújula cuya aguja apunta siempre hacia un lugar al que no se llegará nunca y del cual tampoco hay escapatoria. El -¿él?- se expresa en metáforas, en lógica simbólica, en lenguaje natural, en la ocasional conjugación de ambos en una máquina lógica que procesa lenguaje natural y probablemente de muchas otras maneras.

La gran inteligencia de Parra fue hacer de ese hecho elemental un antipoema.

\section{BIBLIOGRAFÍA}

Borges, Jorge Luis. El Informe de Brodie. Buenos Aires: Emecé, 1970, p. 9.

Link, David. "There must be an Angel. On the beginnings of the Arithmetics of Rays". En Zielinski, Siegfried y David Link (Eds.). Variantology 2. On deep time relations of arts, sciences and technologies. Köln: Walther König, 2006. 15-42.

Proops, Ian. "Wittgenstein on the substance of the world". European Journal of Philosophy. Wiley-Blackwell, Hoboken-New Jersey, 2004, p. 106.

Wittgenstein, Ludwig. Tractatus logico-philosophicus. 1921. Madrid: Alianza, 1973, pp. $53,69,39$. 